\title{
Childhood Pneumonia: Clinical Aspects Associated with Hospitalization or Death
}

Cristiana M.C. Nascimento-Carvalho, Heonir Rocha, Rogério Santos-Jesus and Yehuda Benguigui

\author{
Department of Pediatrics and of Internal \\ Medicine, Faculty of Medicine, Professor \\ Hosannah de Oliveira Pediatric Center, \\ Federal University of Bahia; Aliança \\ Hospital; Salvador, Bahia, Brazil; and Pan \\ American Health Organization, Washington \\ $D C, U S A$
}

\begin{abstract}
Objective: To determine which available information at an Emergency Room (ER) consultation is associated with hospitalization or death among children with pneumonia. Design: Prospective cohort study. Setting: The ER of one university and one private hospital. Measurement: Using stepwise logistic regression we analyzed factors that showed a univariate association. Main Results: Of 2,970 cases, the median age was 1.83 years (range 2 days to 14.5 yrs, mean $2.76 \pm$ $2.72 \mathrm{yrs}) ; 25.8 \%$ were hospitalized and $0.8 \%$ died. Age (2-11 mos, OR 0.4 [0.2-0.6]; 12-59 mos, OR 0.2 [0.1-0.4]; $\geq$ 5yrs, OR 0.1 [0.08-0.3]), malnutrition (OR 2.0 [1.4-2.7]), underlying chronic illness (OR 1.4 [1.1-1.8]), tachypnea (OR 1.8 [1.4-2.4]), chest indrawing (OR 1.7 [1.4-2.2]), and somnolence (OR 1.8 [1.4-2.4]) were associated with hospitalization and age (2-11 mos, OR 0.3 $[0.08-0.8] ; \geq 12$ mos, OR 0.06 [0.02-0.2]), malnutrition (OR 3.1 [1.2-7.7]) and underlying chronic illness (OR 4.3 [1.6-11.0]) were associated with death in the multivariate analysis. Conclusions: Several clinical aspects may be used in assessing need for hospitalization (i.e. young age, malnutrition, underlying chronic illness, tachypnea, chest indrawing and somnolence) for children with pneumonia seen at the ER. Individual intrinsic factors such as age, malnutrition and underlying chronic illness were independently associated with death. Pneumonia should be considered a treatable disease and complete recovery can be achieved in the majority of the cases.

Key Words: Pneumonia, children, clinical signs, hospitalization, mortality, outpatients.
\end{abstract}

Acute respiratory infection, particularly pneumonia, is a major cause of hospitalization and death during childhood in poor areas of the world [1,2]. In order to reduce the high mortality, the World Health Organization (WHO) has developed a Program for the Control of

Received on 12 March 2001; revised 5 September 2001.

Address for correspondence: Dr. Cristiana NascimentoCarvalho, MD, PhD. Department of Pediatrics, Faculty of Medicine, Federal University of Bahia, Rua Prof. Aristides Novis, № 105/1201B - Salvador, Bahia, Brazil, Zip code: 40210730. E-mail: nascimentocarvalho@hotmail.com

This study was supported by the Pan American Health Organization.

The Brazilian Journal of Infectious Diseases 2002;6(1):22-28 (C) 2002 by The Brazilian Journal of Infectious Diseases and Contexto Publishing. All rights reserved.

$1413-8670$
Respiratory Infections through improved case management for children under five years of age [3]. In the mid 1990s, this program was included as a component of the Integrated Management of Childhood Illness (IMCI) Strategy [4], which is currently being proposed as a single and integrated approach to assess, classify and treat children at first level health facilities. The primary goal is to reduce deaths in children aged $<5$ years in the Americas by 100,000, between 1999 and 2002 [5]. By using this approach, pneumonia is diagnosed by the presence of tachypnea defined as: $\geq 60$ breaths/minute among children aged $<2$ months, $\geq 50$ breaths/minute among children aged 2-11 months and $\geq 40$ breaths/minute among children aged 12-59 months. The guidelines used to categorize pneumonia severity include the presence of chest indrawing, somnolence, convulsions, grunting 
when the child is quiet, severe malnutrition and inability to drink, as indicators for hospitalization and parenteral antibiotics [6].

In this study, we sought to evaluate which clinical aspects were associated with hospitalization or death in children with pneumonia at two tertiary health care settings in Salvador, Bahia, Brazil.

\section{Materials and Methods}

Study design and population. We attempted to enroll prospectively every child diagnosed with pneumonia, from September, 1997, to October, 1999, at the Emergency Room (ER) of the Professor Hosannah de Oliveira Pediatric Center (PHOPC), a university hospital, and at the Pediatric ER of the Aliança Hospital $(\mathrm{AH})$, a private hospital, in Salvador, Brazil. Data were collected on a standardized data entry form (Figure 1) to extract demographic and clinical information. The diagnosis of pneumonia was based on either a finding of simultaneous cough and tachypnea [3], or radiologically confirmed infiltrate. For children aged five years or older, tachypnea was defined as a respiratory rate $\geq 40$ breaths/minute. Chest X-ray was read by the pediatrician on duty during the consultation. All patients were treated with antibiotics. All ER records were reviewed once a week, beginning in March,1998, at the PHOPC, and in May,1998, at the AH. The data entry forms of those patients characterized as having pneumonia whose forms were not filled out prospectively by the primary physician, were filled out retrospectively. Admission to the hospital or death were registered after cross-reference with the computer file of the respective hospital and the clinical records of those patients who died were reviewed for the collection of additional data.

Data analysis. Statistical analyses were performed using the Statistical Package for the Social Sciences (SPSS 9.0). Age was categorized into four groups: $<2$ months, 2-11 months, 12-59 months, $\geq 5$ years. Malnutrition was defined as weight for age under -2SD using the National Center for Health Statistics (NCHS-
USA) pattern.[7] Fever was defined as axillary temperature $>37.5^{\circ} \mathrm{C}$ during the consultation. Association between dependent and independent variables was initially assessed by univariate analysis with the Pearson chi square test or Fisher's exact test as appropriate. The statistical tests were two tailed, with a significance level of 0.05 . Independent variables that gave significant results in the univariate analysis were used in the four stepwise multiple logistic regression analysis to determine their independent effect on the dependent variables. Odds ratios and their corresponding 95\% confidence intervals were calculated. The study was approved by the institutional review board of each hospital and by the Ethics Committee of the Faculty of Medicine of the Federal University of Bahia.

\section{Results}

A total of 2,970 cases were consecutively identified among 2,795 children. The intervals between separate episodes in the patients with more than one infection were, in all instances, longer than 1 month. There were $54.1 \%$ males and $45.9 \%$ females. The median age was 1.83 years (range 2 days to 14.5 years, mean $2.76 \pm$ 2.72 years). Tachypnea was reported in $62.3 \%$ of all cases. Chest X-ray was performed in $96.0 \%$ and radiologically confirmed infiltrate was described in $97.9 \%$. Hospitalization occurred in $25.8 \%$ of the cases and mortality was $0.8 \%$; death occurred within the first 24 hours of admission in $47.8 \%$. Underlying chronic illness was reported in $31.1 \%$ of the cases and the most frequent ones were: asthma/increased bronchial reactivity $(55.0 \%)$, cardiopathy $(13.3 \%)$, gastroesophageal reflux (5.9\%), anemia (5.2\%), neuropathy (3.6\%), genetic syndrome (3.1\%), chronic liver disease (1.9\%). Table 1 shows significant differences in clinical aspects in relation to hospitalization; no significant differences were noticed in the frequency of cough, fever, wheezing, crackles, or in the distribution of gender. Table 2 shows the association of several clinical aspects with death; no significant differences were found in the frequency of 
Table 1.Clinical aspects associated with hospitalization in children with pneumonia

\begin{tabular}{|c|c|c|c|c|c|c|}
\hline \multirow[b]{2}{*}{ Characteristic* } & \multicolumn{2}{|c|}{ Hospitalization } & \multicolumn{2}{|c|}{ Univariate } & \multicolumn{2}{|c|}{ Multivariate } \\
\hline & Yes $(N=503)$ & No $(N=1100)$ & p value & OR (CI 95\%) & p value & OR (CI 95\%) \\
\hline \multicolumn{7}{|l|}{ Age } \\
\hline$<2 \operatorname{mos}$ & 49 (9.7) & $29(2.6)$ & & & & \\
\hline $2-11 \mathrm{mos}$ & $169(33.6)$ & $248(22.6)$ & 0.000 & $0.4(0.2-0.7)$ & & $0.4(0.2-0.6)$ \\
\hline $12-59 \operatorname{mos}$ & $249(49.5)$ & $634(57.6)$ & 0.000 & $0.2(0.1-0.4)$ & & $0.2(0.1-0.4)$ \\
\hline$\geq 5 \mathrm{yrs}$ & $36(7.2)$ & $189(17.2)$ & 0.000 & $0.1(0.06-0.2)$ & 0.000 & $0.1(0.08-0.3)$ \\
\hline Malnutrition & $110(21.9)$ & $101(9.2)$ & 0.000 & $2.8(2.1-3.7)$ & 0.000 & $2.0(1.4-2.7)$ \\
\hline $\begin{array}{l}\text { Underlying illness } \\
\text { (chronic) }\end{array}$ & $183(36.4)$ & $314(28.5)$ & 0.002 & $1.4(1.1-1.8)$ & 0.01 & $1.4(1.1-1.8)$ \\
\hline Inability to drink & $31(6.2)$ & $36(3.3)$ & 0.008 & $1.9(1.2-3.2)$ & 0.2 & $1.5(0.8-2.6)$ \\
\hline Tachypnea & $395(78.5)$ & $647(58.8)$ & 0.000 & $2.6(2.0-3.3)$ & 0.000 & $1.8(1.4-2.4)$ \\
\hline Chest indrawing & $305(60.6)$ & $440(40.0)$ & 0.000 & $2.3(1.9-2.9)$ & 0.000 & $1.7(1.4-2.2)$ \\
\hline Somnolence & $137(27.2)$ & $157(14.3)$ & 0.000 & $2.2(1.7-2.9)$ & 0.000 & $1.8(1.4-2.4)$ \\
\hline
\end{tabular}

*Results are reported in $\mathrm{n}(\%)$ 


\section{Epidemiologic surveillance of lower respiratory tract infections (LRTI) among Latin American children - Salvador - Bahia}

1a.Baseline Data: (to be filled out at the hospital)

Hospital code:

Patient code:

Patient ID (hospital):

Consultation Date

Patient name:

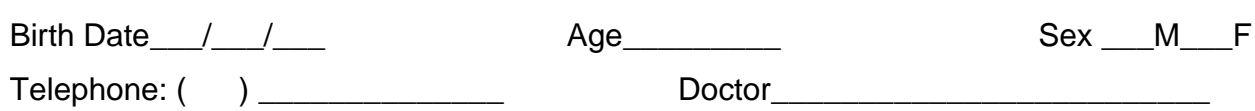

Address(district/city)

Father profession

Mother profession

Health insurance

Household Smoker

$(\mathrm{Y} / \mathrm{N}) \quad$ Attending Day-care center

(Y/N) Going to school

$(\mathrm{Y} / \mathrm{N})$

Chronic illness___ $(\mathrm{Y} / \mathrm{N})$

Did the child take any antimicrobial to treat this illness

$(\mathrm{Y} / \mathrm{N})$

Which?

Which? until when?

2.Clinical Data: (to be filled out at the hospital):

Cough $(\mathrm{Y} / \mathrm{N})$

Respiratory rate

Temp

$\stackrel{\circ}{C}$

Weight

Ability to drink $(\mathrm{Y} / \mathrm{N}) \quad$ Chest indrawing

$(\mathrm{Y} / \mathrm{N}) \quad$ Crackles

$(\mathrm{Y} / \mathrm{N}) \quad$ Wheezing

$(\mathrm{Y} / \mathrm{N})$

Somnolence __ $(\mathrm{Y} / \mathrm{N})$

Chest X-ray performance___ $(\mathrm{Y} / \mathrm{N}) \quad$ Result:

$\square$ 1.Normal

$\square$ 2.Interstitial infiltrate

$\square$ 3.Alveolar infiltrate

$\square$ 4.Interstitial and alveolar infiltrate

$\square$ 5.Pleural efusion

1b. Baseline Data: (to be filled out at the hospital)

Where did the patient present:

$\square$ 1.Emergency Room $\square$ 2.Ambulatory Room $\square$ 3.Other (specify) Information Source:

1.Clinical record___ $(\mathrm{Y} / \mathrm{N})$

2.Doctor $(\mathrm{Y} / \mathrm{N})$

3.Family/patient

$(\mathrm{Y} / \mathrm{N})$

3.Evolution: (to be filled out at the hospital)

Was the patient admitted to the hospital $(\mathrm{Y} / \mathrm{N})$

If hospitalized, what happens after 10 days of admittance:

1.Death__ (Y/N) 2.discharge__ (Y/N) 3.Still in the hospital

(Y/N) Discharge Date

4.Microbiologic Data: (to be filled out at the laboratory)

Blood culture performance ___ $(\mathrm{Y} / \mathrm{N})$

Result: $\square$ 1.S. pneumoniae

Pleural fluid culture performance

Result: $\square$ 1.S. pneumoniae

$S$. pneumoniae: serotype

Penicillin resistance

$\square$ 2.H. influenzae $\square$ 3.Other (specify) $(\mathrm{Y} / \mathrm{N})$

$\square$ 2. H. influenzae

$\square$ 3.Other (specify) (Adolfo Lutz Institute) MIC

www.infecto.org.br/bjid.htm 
Table 2. Clinical aspects associated with death in children with pneumonia 
cough, inability to drink, fever, crackles, wheezing, somnolence or in the distribution of gender. There were 1,367 and 1,208 cases excluded from the multivariate analysis of hospitalization and death, respectively, due to lack of information of any of the predictor variables. The underlying chronic illness reported by children who died were: cardiopathy (7/14), neuropathy (3/14), asthma (1/14), gastroesophageal reflux (1/14), congenital infection(1/14), hypothyroidism (1/14).

\section{Discussion}

This study has several important characteristics: first, there were a great number of patients studied; second, the study was carried out at two hospitals which give tertiary health care; and third, the timing was prospective.

Our data demonstrated that tachypnea, chest indrawing, somnolence, malnutrition, underlying chronic illness, and young age were independently associated with hospitalization for pneumonia (Table 1), suggesting that they may be used in deciding the appropriateness of hospitalization for children with pneumonia. These results are in agreement with previous studies [8-11]. We failed to show an independent association with inability to drink and hospitalization. Although it has been found to be an appropriate criterion for defining very severe disease [11], it may overlap with other clinical aspects.

This study also provided evidence that basic individual intrinsic factors such as age, malnutrition, and underlying chronic illness, are independently associated with death (Table 2). According to the WHO, over $30 \%$ of all deaths in children under five years of age in poor countries, occur during the first months of life [12], and $70 \%$ those deaths are attributable to pneumonia, diarrhea, measles, or malaria [13]. Recent estimates suggest a strong and consistent relationship between malnutrition (measured as poor anthropometric status) and an increased risk of death from acute respiratory infection [14]. Therefore, preventive strategies like vaccination, which is effective in very young children, and nutrition education programs are remarkably important $[15,16]$. We think that further studies are needed to clarify the independent association of tachypnea with death in children with pneumonia, as in this investigation where that association demonstrated a borderline significance.

We included patients diagnosed with pneumonia in accordance with the WHO criteria (i.e. tachypnea) in the analysis [3] because chest X-ray was not feasible in all cases, and tachypnea has been exhaustively demonstrated to be an excellent predictor of radiologically defined pneumonia [8,9,17-25]. The weight for age z-score was not used to evaluate nutritional status because information on the height of each child is not collected during consultations in the ERs. Our results may not be generalized to the industrialized world where malnutrition in children is rare [26, 27].

Our mortality rate $(0.8 \%)$ was remarkably low. This may be attributable to the fact that this study was conducted at two tertiary health care settings in an urban area. High pneumonia mortality has been reported mainly in rural areas in poor countries because of difficult access to health care $[4,6,23]$.

From the data shown, one can infer that pneumonia may be considered a treatable disease and complete recovery may be achieved in the majority of the cases. However, some patients are prone to fatal outcomes because of several different intrinsic factors (i.e. young age, malnutrition, underlying chronic illness).

\section{Acknowledgments}

We thank Maria Regina A. Cardoso, MD, PhD, for her technical assistance in the analysis, and every pediatrician, nurse, and medical student, working in the ERs of the participant hospitals, for collaborating on this study.

\section{References}

1. Denny F.W., Loda F.A. Acute respiratory infections are the leading cause of death in children in developing countries. Am J Trop Med Hyg 1986;35:1-2. 
2. Garenne M., Ronsmans C., Campbell H. The magnitude of mortality from acute respiratory infections in children under 5 years in developing countries. World Health Stat Q 1992;45:180-91.

3. World Health Organization. Case management of acute respiratory infections in developing countries: report of a working group meeting. Document WHO/RSD/ 85.15 Rev 1. Geneva: WHO, 1985.

4. Benguigui Y., ed. Controle das Infecções Respiratórias Agudas: Implementação, Acompanhamento e Avaliação. Washington, D.C.: OPAS, c1997.

5. OPS. Niños sanos: la meta de 2002. Informe térnico del lanzamiento de la meta Niños sanos: la meta de 2002. Washington, D. C.: OPS, 2000. (Série HCT/AIEPI 39-E)

6. Benguigui Y., ed. Infecções Respiratórias Agudas: Fundamentos Técnicos das Estratégias de Controle. Washington, D. C.: OPS, c1997.

7. Vasconcelos F.A.G. Avaliação Nutricional de Coletividades: textos de apoio didático. Florianópolis: Editora da UFSC, 1993.

8. Shann F., Hart K., Thomas D. Acute lower respiratory infections in children: possible criteria for selection of patients for antibiotic therapy and hospital admission. Bull WHO 1984;62:749-53.

9. Spooner V., Barker J., Tulloch S., et al. Clinical signs and risk factors associated with pneumonia in children admitted to Goroka Hospital, Papua New Guinea. J Trop Pediatr 1989;35:295-300.

10. Barker J., Gratten M., Riley I., et al. Pneumonia in Children in the Eastern Highlands of Papua New Guinea: A Bacteriologic Study of Patients Selected by Standard Clinical Criteria. J Infect Dis 1989;159:348-52.

11. Shann F., Barker J., Poore P. Clinical signs that predict death in children with severe pneumonia. Pediatr Infect Dis J 1989;8:852-5.

12. Gadomski A. Epidemiology and etiology of acute respiratory infections, particularly pneumonia, in developing countries. WHO, EM/INC.MTG.ARI/3, 1989.

13. OPS, Organização Panamericana de Saúde. Melhorando a saúde das Crianças - AIDPI: O Enfoque Integrado. OPS: Washington, D C, Série HCT/AIEPI 38.P/06-20005M, 2000.

14. Rice A.L., Sacco L., Hyder A., Black R.E. Malnutrition as an underlying cause of childhood deaths associated with infectious diseases in developing countries. Bull World Health Organ 2000;78:1207-21.

15. Victora C.G., Kirkwood B.R., Ashworth A., et al. Potential interventions for the prevention of childhood pneumonia in developing countries: improving nutrition. Am J Clin Nutr 1999;70:309-20.
16. Ladzani R., Steyn N.P., Nel J.H. An evaluation of the effectiveness of nutrition advisers in three rual areas of northern province. S Afr Med J 2000;90;811-6.

17. Leventhal J.M. Clinical predictors of pneumonia as a guide to ordering chest roentgenograms. Clin Pediatr 1982;21:730-4.

18. Cherian T., John T.J., Simoes E., et al. Evaluation of simple clinical signs for the diagnosis of acute lower respiratory infection. Lancet 1988;2:125-8.

19. Campbell H., Byass P., Greenwood B.M. Simple clinical signs for diagnosis of acute lower respiratory infections. Lancet 1988;2:742-3.

20. Harari M., Shann F., Spooner V., et al. Clinical signs of pneumonia in children. Lancet 1991;338:928-30.

21. Mulholland E.K., Simoes E.A.F., Costales M.O.D., et al. Standardized diagnosis of pneumonia in developing countries. Pediatr Infect Dis J 1992;11:77-81.

22. Korppi M. Physical signs in childhood pneumonia. Pediatr Infect Dis J 1995; 14: 405-6.

23. Dai Y., Foy H.M., Zhu Z., et al. Respiratory rate and signs in roentgenographically confirmed pneumonia among children in China. Pediatr Infect Dis J 1995; 14:48-50.

24. Taylor J.A., Beccaro M.D., Done S., Winters W. Establishing clinically relevant standards for tachypnea in febrile children younger than 2 years. Arch Pediatr Adolesc Med 1995; 149:283-7.

25. Palafox M., Guiscafré H., Reyes H., et al. Diagnostic value of tachypnoea in pneumonia defined radiologically. Arch Dis Child 2000;82:41-5.

26. Karp R.J. Head Start, nutrition, and problems of poverty in childhood. J Am Coll Nutr 1999; 18:100-1.

27. Oberg C. The interplay of poverty and adverse health outcomes. Minn Med 2000;83:20-1. 